\title{
DESARROLLO URBANO Y EVOLUCION DE LA POBLACION: ESPAÑA 1787-1930*
}

DAVID-SVEN REHER Universidad Complutense

Entre las características más sobresalientes de la revolución industrial en Europa destaca el crecimiento espectacular de las ciudades. Las implicaciones de este proceso de urbanización para la dinámica más amplia del comportamiento demográfico de las sociedades europeas de los siglos XIX y $\mathrm{xx}$ son de una importancia fundamental para nuestra comprensión de los últimos dos siglos de historia europea. Parecería razonable suponer que el peso creciente de las ciudades condicionaba no sólo los comportamientos vitales de sus propios residentes, sino que funcionaba como catalizador de cambios en toda la sociedad. A fin de abordar esta cuestión, es preciso plantearse una serie de interrogantes acerca del papel desempeñado por las ciudades en la Europa de la revolución industrial. ¿Hasta qué punto tendieron a compensar los núcleos crecientes de población urbana, con niveles supuestamente inferiores de nupcialidad y fecundidad y superiores de mortalidad, a las tasas de crecimiento natural, claramente insostenibles, del mundo rural? ¿Fueron las poblaciones urbanas pioneras en la transición demográfica o seguían un modelo similar al de las áreas rurales? (Livi Bacci, 1971: 102-111; Lesthaeghe, 1977: caps. 5 y 6; Knodel, 1974: 206-222). ¿En gué diferían estos comportamientos al ir creciendo la ciudad? ¿Influyeron o no las ciudades, y en qué medida, en las áreas rurales circundantes, de modo que no sólo habrían sido protagonistas de distintos modelos de comportamiento y cambio demográficos, sino que también agentes de cambio en las áreas rurales?

Naturalmente, España también participó en el gran movimiento europeo hacia la urbanización de los siglos $\mathrm{xIX}$ y $\mathrm{xX}$, aunque a un paso algo más lento. Esta urbanización creciente y sus consecuencias para el desarrollo demográfico en España son los temas centrales de este artículo. Massimo Livi Bacci (1968),

* Una primera versión de este trabajo se presentó en el Seminario sobre Comparative Urban Population Development in Western Europe, 1750-1920, celebrado en Liverpool en septiembre de 1984. Las actas de dicho Seminario están en vías de publicación: R. LAWTON y W. R. LEE (eds.), Population and Urban Development in Western Europe c. 1750-1920. Quisiera agradecer a Benito Cachinero, Susan Watkins, Eugene Hammel y Ginés López-Oliver sus comentarios sobre una versión anterior. 
William Leasure (1963) y Joaquín Arango (1980) han tratado ya, aunque con diferente énfasis, el papel que desempeñó la urbanización en la transición demográfica española. Sigue siendo necesario, sin embargo, un estudio que trate de forma sistemática las diferencias entre comportamientos demográficos rurales y urbanos. Con la esperanza de rellenar este hueco vamos a analizar las diferencias entre ambos medios, así como las influencias recíprocas que los han unido. Empezaremos en el siglo xvirl, cuando España era todavía un país fundamentalmente rural, y llegaremos hasta 1930, momento en el que el proceso de urbanización estaba en su apogeo y el 26,5 por 100 de la población vivía en áreas que bien se pueden calificar de «urbanas». Este empeño implica abordar algunos puntos clave sobre urbanización y desarrollo demográfico en España. Se procurará definir y diferenciar de forma precisa entre comportamientos rurales y urbanos, para poder plantear, a su vez, la cuestión de si el cambio demográfico no seguiría una cronología diferente para cada zona. Asimismo se analizarán las posibles consecuencias del peso urbano a la hora de estimular cambios de comportamiento en el mundo rural. En última instancia, el papel desempeñado por las zonas urbanas en el cambio demográfico es el tema central de este trabajo; un papel cuya importancia va en aumento a medida que va creciendo el peso relativo de las ciudades y que puede convertirse en factor clave para entender la evolución de la sociedad española.

Dos fuentes de documentación han resultado fundamentales para la elaboración de este trabajo: los censos y el Registro Civil. Existen censos para $1787,1797,1857,1860,1877,1887,1897,1900,1910,1920,1930$; pero, por distintas razones, hemos tenido que descartar los de 1797, 1857, 1877 y 1897. Hemos complementado los datos censales con cifras de matrimonios, nacidos vivos y defunciones de los libros de Movimiento de la Población, que apareció esporádicamente durante el siglo XIX y de forma continuada a partir de $1900^{1}$. A pesar de que los datos del Registro Civil presentan problemas tanto en la definición de "nacidos vivos» como en la no distinción entre nacidos legítimos e ilegítimos en 1887 y 1930, hemos utilizado las estadísticas de nacidos vivos para elaborar índices demográficos y hemos calculado estimaciones de nacimientos legítimos donde faltaban (Gómez Redondo, 1984). Ciertas provincias, y en especial Murcia, revelaron un considerable subregistro de la natalidad femenina (por ejemplo, razón de masculinidad al nacer superior a 150 en Murcia y Lorca), que fue subsanado por una medida muy sencilla y útil a la vez. Aquellas razones superiores a 115 fueron ajustadas a ese

- Junta General Estadística del Reino, Memoria sobre el movimiento de la población de España en los años 1858, 1859, 1860, y 1861, Madrid, 1863; Instituto Geográfico y Estadístico, Movimiento de la población de España en el decenio 1861 a 1870, Madrid, 1877; Movimiento de la población de España, septenio de 1886-1892, Madrid, s. f.; Movimiento de la población de España (anual, desde 1900). 
nivel. Aunque esto sigue manteniendo cierto subregistro de la natalidad femenina, lo reduce a niveles mínimos sin correr el riesgo de agregar nacimientos falsos.

El proceso para elaborar los diferentes índices fue bastante sencillo. Las cifras relativas a poblaciones urbanas (por sexo, edad, estado civil y los nacidos vivos) fueron sustraídas de las de la población total para obtener así el subgrupo de la población rural. Resulta de gran ayuda el hecho de que los censos y estadísticas vitales españoles siempre distingan entre la capital y su provincia, y que incluyan también los municipios de cierta consideración (normalmente, los mayores de 10.000 habitantes). Siempre que haya existido total desagregación de los datos, los índices se han basado en la totalidad de poblaciones urbanas. Sin embargo, cuando únicamente existe información acerca de la capital y el resto de la provincia, caso de los censos de 1860 y 1900 , se ha considerado a las capitales como representativas de la totalidad de las poblaciones urbanas, con el consiguiente grado de incertidumbre en los resultados. En este artículo vamos a dar un énfasis especial a la nupcialidad y la fecundidad, pues si la primera es, de entre todas las variables demográficas, la más susceptible a determinantes sociales y debería, por tanto, estar muy influida por la vida urbana, la fecundidad está considerada la clave de la transición demográfica. Como indicador general de nupcialidad hemos usado Im, elaborado originariamente por Ansley Coale para el European Fertility Project, de Princeton, y que simultáneamente posee dos importantes ventajas, ya que mide, por un lado, la edad y la incidencia del matrimonio y, por otro, al relacionar la incidencia del matrimonio con la fecundidad experimentada por las hutteritas, implica una estandarización por edades que da un mayor peso a los grupos de edad más fértiles (Lestaeghe, 1977: 47)². Im será complementado con datos referidos a la soltería definitiva y a la edad al matrimonio, siempre que sea necesario. Como indicadores de fecundidad legítima hemos utilizado dos: la tasa de fecundidad marital (TFM), producto de dividir la tasa de na-

${ }^{2}$ Véase Coale (1965 y 1969). Im consiste en:

$$
\text { Im }=\frac{\Sigma m i \cdot F i}{\Sigma w i \cdot F i}
$$

Donde $m i$ son las mujeres casadas a la edad $i$; wi son las mujeres de edad $i$, y $F i$ es la fecundidad de las mujeres hutteritas entre 1921 y 1930 . Estos niveles de fecundidad son: $15-19=0,300 ; 20-24=0,550 ; \quad 25-29=0,502 ; \quad 30-34=0,447 ; \quad 35-39=0,406 ; 40-44=0,222, y$ $45-49=0,061$. Las distintas distribuciones por edades de los censos españoles nos llevaron a modificar estas tasas, bajo la suposición de que las tasas no varían dentro de cada grupo. Este procedimiento implica una ligera sobreestimación de la fecundidad en los grupos más jóvenes y una ligera subestimación en los más viejos. Para 1787, las tasas son 0,511 (16-25) 0.453 (25-40) y 0,150 (40-50). Para los censos restantes son $0,350,0,540,0,491$, $0,439,0,369,0,190$ y 0,149 . 
talidad por el porcentaje de mujeres casadas en edad fértil (16-50) con respecto al total de la población ${ }^{3}$, y, en segundo lugar, $I g$, también propuesto por Ansley Coale, de Princeton, y que compara el número de nacimientos de una población con los que se hubieran producido en caso de tener la mayor fecundidad conocida, la de las mujeres hutteritas ${ }^{4}$. Incluyendo sólo mujeres casadas en estos cálculos, a diferencia de la tasa de natalidad, la TFM y, sobre todo, Ig minimizan con éxito la influencia de la estructura por edades en las diferentes poblaciones. Puesto que no es posible obtener tasas de fecundidad específicas antes de $1920, \mathrm{Ig}$ es el indicador que mejor responde a nuestros propósitos.

\section{Areas urbanas: una definición}

Antes de analizar con detalle el comportamiento demográfico urbano es conveniente delimitar claramente el sentido que se da a "urbano». El éxito de todo análisis posterior dependerá de la viabilidad histórica de esta definición. Así, pues, ¿qué es una ciudad? Dos han sido los enfoques tradicionales, en realidad complementarios entre sí. Según el primero se considera ciudad a una aglomeración humana más o menos grande que está bajo un ayuntamiento. El límite a partir del cual una aglomeración humana empieza a ser , ciudad y deja de ser pueblo es tema de múltiples discusiones. En el caso español, se han propuesto durante este siglo los umbrales de 5.000, 10.000 y 20.000 habitantes (Leasure, 1963: 273; Rodríguez Osuna, 1983: 26-28; Bairoch, 1977: 17). La otra perspectiva considera urbanas a las poblaciones mayoritariamente dedicadas a actividades no agrarias; en otras palabras, lo urbano se define por la menor importancia de la tierra y el trabajo agrícola para la población activa (Díez Nicolás, 1972: 46-49). Ambas aproximaciones tienen

${ }^{3}$ La TFM se calcula con arreglo a la siguiente ecuación:

$$
T F M=\text { tasa de natalidad }: \frac{\text { mujeres casadas } 16-50}{\text { población total }}
$$

Hay que recordar que aquí la tasa de natalidad se calcula a partir de los nacimientos legítimos. De no hacerse así, hay que compensar los nacimientos ilegítimos a fin de no sobreestimar la TFM. Véase Livi Bacci (1968: 95).

- La ecuación de I $g$ es la siguiente:

$$
I g=\frac{N}{\sum m i \cdot F i}
$$

Donde $N$ es el total de nacimientos legítimos; $m i$ es el número de mujeres casadas a la edad $i$, y $F i$ es la fecundidad de las hutteritas. 
mucho de válido, sin duda. La población activa muestra con claridad una diferencia entre lo rural y lo urbano; pero la mera aglomeración de población (de la que participan todas las áreas urbanas) también afecta al comportamiento, como se verá más adelante. Sin embargo, ninguna de ellas carece de inconvenientes en el caso de España, y de forma especial cuando tratamos con fuentes históricas. Ciertas zonas de la Península se caracterizan por la existencia de agrociudades, pueblos grandes que se componen de agricultores $\mathbf{y}$ jornaleros. Podemos trazar un arco que desde Alicante y Murcia, en el Este, se prolonga a través de Andalucía y delimita una región que ya en la época romana tenía importantes núcleos de población mayoritariamente agrícolas. Las proporciones de esos núcleos son a veces sorprendentemente altas en el siglo xvirI -Murcia, 75,7 por 100; Málaga, 53,6 por 100; Córdoba, 61,61 por 100; Lorca, 82,4 por 100; Jerez de la Frontera, 58,2 por 100 (cifras para 1787)-, y persisten durante el período en que nos movemos. Mientras en el caso de Murcia esa circunstancia parece deberse a poblaciones rurales que rodean un núcleo urbano, y que están bajo el mismo municipio, en la mayor parte de casos restantes la población agraria vive dentro de las murallas de la ciudad. Asturias plantea una situación similar, aunque más a causa de definiciones administrativas que por su conformación histórica: al igual que partes de Galicia y del norte de Portugal, presenta proporciones elevadísimas de población dedicada al campo y que vive en núcleos cuyo tamaño nos llevaría a creer que son de naturaleza urbana. Es, sin embargo, la costumbre de agrupar parroquias rurales bajo un solo ayuntamiento la que nos oculta una situación bien differente. Pero también se da el caso contrario: numerosas ciudades y capitales de provincia, sobre todo en Castilla, pueden tener menos de 10.000 habitantes y, sin embargo, escapan a la categoría «rural» por su papel en la administración real, eclesiástica o provincial, o por su función histórica como centros universitarios o de élite.

Por último, cualquier definición de población urbana encontrará en España otra dificultad. Con pocas excepciones, la mayoría de los pueblos incluyen un componente apreciable de población dedicada a la agricultura y, aunque los elevadísimos niveles que mencionamos anteriormente no son en absoluto la regla general, la mayoría de los pueblos tienen entre un cuarto y la mitad de su población activa ocupada en tareas del campo. Esto es debido al débil y sincopado proceso de industrialización español y a su concentración en unos pocos puntos, en especial hasta 1900.

En definitiva, hemos escogido una definición de población urbana que, aunque no exenta de objeciones, tiene las ventajas de ser sencilla, aplicable sin dificultad a los datos de los siglos xIX y xx y sensible a algunos de los problemas expuestos. Para que un municipio pueda ser considerado como entidad urbana debe cumplir, al menos, uno de los dos requisitos: tener una población su- 
perior a 20.000 habitantes o, si la población fuese menor, ser capital de provincia. El umbral de 20.000 habitantes, en lugar de, por ejemplo, 10.000, limitará los efectos distorsionadores de las agrociudades, aunque no excluirá a aquellas que concentran poblaciones realmente grandes. Al considerar también las capitales de provincia, sea cual sea su tamaño, reconocemos su capacidad de atraer durante este período a quienes acabarían ocupados en actividades no agrarias. Aunque sólo ocasionalmente son industriales, es habitual que muestren altas concentraciones de población activa en el sector servicios y, durante el siglo xvin al menos, que tengan una parte importante de su población trabajando para la Iglesia. Por estas razones, el no tener una población activa dedicada fundamentalmente a tareas agrícolas completa el requisito para ser ciudad.

Un análisis de la distribución de la población activa en el censo de Floridablanca de 1787 no sólo apoyará partes de esta argumentación, sino que servirá, además, de introducción a los núcleos urbanos históricos de España. Este censo contiene una distribución de la población activa bastante rudimentaria, pero que se presta a una reagrupación por sectores. En la tabla 1 se exponen los porcentajes de población ocupados en actividades agrícolas según el tamaño del núcleo.

\section{TABLA 1}

Proporción de la población activa ocupada en actividades agrícolas, 1787

\begin{tabular}{|c|c|c|c|c|c|c|c|}
\hline & & & PRO & ORCION E & N ACTIVID & DES AGRIC & AS \\
\hline & Población & & $<20 \%$ & $20-34 \%$ & $35.49 \%$ & $>49 \%$ & Total \\
\hline$>100.000 \ldots$ & $\begin{array}{lllll}\ldots & \ldots & \ldots & \ldots & \ldots\end{array}$ & $\stackrel{n}{\%}$ & $\begin{array}{r}1 \\
50\end{array}$ & & $\begin{array}{r}1 \\
50\end{array}$ & & $\begin{array}{r}2 \\
100\end{array}$ \\
\hline $50.000-99.999$ & $\begin{array}{lllll} & \ldots & \ldots & \ldots & \ldots\end{array}$ & $\%$ & & $\begin{array}{r}2 \\
40\end{array}$ & $\begin{array}{r}1 \\
20\end{array}$ & $\begin{array}{r}2 \\
40\end{array}$ & $\begin{array}{r}5 \\
100\end{array}$ \\
\hline $20.000-49.999$ & $\begin{array}{lllll} & \ldots & \ldots & \ldots & \ldots\end{array}$ & $\stackrel{n}{\mathscr{0}}$ & $\begin{array}{r}2 \\
20\end{array}$ & $\begin{array}{r}2 \\
20\end{array}$ & & $\begin{array}{r}6 \\
60\end{array}$ & $\begin{array}{r}10 \\
100\end{array}$ \\
\hline $10.000-19.999$ & $\begin{array}{llllll}\ldots & \ldots & \ldots & \ldots & \ldots\end{array}$ & $\infty^{\mathrm{n}}$ & $\begin{array}{r}1 \\
10\end{array}$ & 20 & 20 & $\begin{array}{r}5 \\
50\end{array}$ & $\begin{array}{r}10 \\
100\end{array}$ \\
\hline$<10.000$ (a) & $\begin{array}{lllll}\ldots & \ldots & \ldots & \ldots & \ldots\end{array}$ & n & $\begin{array}{r}3 \\
18\end{array}$ & $\begin{array}{r}8 \\
47\end{array}$ & $\begin{array}{r}6 \\
35\end{array}$ & & $\begin{array}{r}17 \\
100\end{array}$ \\
\hline Total ... & $\begin{array}{lllllll}\cdots & \ldots & \ldots & \ldots & \ldots & \ldots\end{array}$ & $\%$ & $\begin{array}{r}7 \\
16\end{array}$ & $\begin{array}{l}14 \\
33\end{array}$ & $\begin{array}{l}10 \\
23\end{array}$ & $\begin{array}{l}12 \\
28\end{array}$ & $\begin{array}{r}43 \\
100\end{array}$ \\
\hline
\end{tabular}

(a) No incluye los municipios con menos de 6.000 habitantes.

Fuente: Censo de Floridablanca. 
En primer lugar, es evidente que la presencia más o menos apreciable de población rural en las ciudades es un hecho en la España urbana del siglo xvil. En unos pocos casos, menos del 20 por 100 de la población activa se dedica a la agricultura y, dentro de los mismos, los porcentajes más pequeños se deben (con la excepción de Gerona) a la preponderancia de contingentes mi. litares: Palma de Mallorca, 4,4 por 100; Cartagena, 8,9 por 100, y La Coruña, 11,0 por 100 . Fuera de estas excepciones, la presencia de población agrícola es importante, hasta el punto de que en más de la mitad de los núcleos sobrepasa el tercio de la población activa. No obstante, la importancia de la población agrícola no se distribuye de manera uniforme en las ciudades. Mientras el grupo que contiene los núcleos urbanos de mayor tamaño es demasiado pequeño para derivar alguna conclusión, los siguientes sí nos lo permiten. Los municipios de medio y gran tamaño se caracterizan por unas proporciones de trabajadores agrícolas prácticamente inexistentes en las capitales de provincia más pequeñas. De los 27 municipios mayores de España, casi la mitad (concretamente 13) tienen actividades agrícolas que ocupan a más del 50 por 100 de su fuerza de trabajo. De estas 13 agrociudades, sólo Oviedo escapa a una localización en el Mediterráneo, que tiene sus mayores concentraciones en Murcia (Murcia y Lorca) y en la Andalucía oriental (Granada, Almería, Málaga, Jaén y Córdoba). Las capitales pequeñas siguen siendo, no obstante, el grupo que tiene la proporción más reducida de población activa agrícola. Este hecho nos ayudará, más tarde, a comprender los modelos de matrimonio que se producen en estas áreas urbanas de pequeño tamaño.

Otro sector de considerable importancia en las áreas urbanas durante el siglo xviri es el de los servicios, entendido como el conjunto de actividades no agrícolas ni industriales (Pérez Moreda, 1985). Esta relevancia, que se prolongará durante el siglo $\mathrm{xIx}$, si bien perdiendo fuerza, se fundamenta en la naturaleza de la ciudad preindustrial como centro de atracción del poder. Era allí donde los nobles preferían residir; donde la Iglesia concentraba la mayor parte de sus rentas y donde se localizaban los cargos más codiciados; donde estaba la Universidad, y donde el servicio doméstico podía encontrar trabajo más fácilmente. En otras palabras, las ciudades españolas atraían importantes volúmenes de población sin relación directa con la producción económica, aunque algunos grupos, en especial la Iglesia y la nobleza, movían cantidades considerables de riqueza. La ciudad industrial no llegaría a ser la forma dominante de organización económica hasta bien entrado el siglo $\mathbf{x x}$. Un vistazo a la tabla 2 revela la importancia de este sector en las poblaciones urbanas. Al menos la mitad de las ciudades españolas tiene más del 33 por 100 de su población activa ocupada en el sector servicios. Su tamaño, y en particular la parte correspondiente al servicio doméstico, tiende a disminuir según crece la población agrícola. De las 12 agrociudades más importantes, 11 tienen 
un sector terciario que no llega al tercio de su población activa, y suponen el 80 por 100 de las ciudades cuyo sector servicios es inferior al 20 por 100 de la población total. Por último, debe señalarse que el sector servicios es el más importante de aquellas pequeñas capitales de provincia, sobre todo en el grupo con menos de 10.000 habitantes; el 61 por 100 de estas capitales tiene más del tercio de su población ocupada en los servicios.

\section{TABLA 2}

Proporción de la población activa ocupada en el sector servicios, 1787

\begin{tabular}{|c|c|c|c|c|c|c|c|}
\hline & \multirow[b]{2}{*}{ Población } & & \multicolumn{2}{|c|}{ PROPORCION EI } & N SECTOR & \multicolumn{2}{|c|}{ SERVICIOS (a) } \\
\hline & & & $<20 \%$ & $20-34 \%$ & $35.49 \%$ & $>49 \%$ & Total \\
\hline$>100.000 \ldots$ & $\begin{array}{lllll}\ldots & \ldots & \ldots & \ldots & \ldots\end{array}$ & n & & $\begin{array}{r}1 \\
50\end{array}$ & & $\begin{array}{r}1 \\
50\end{array}$ & $\begin{array}{r}2 \\
100\end{array}$ \\
\hline $50.000-99.999$ & $\begin{array}{lllll}\ldots & \ldots & \ldots & \ldots & \ldots\end{array}$ & $\%$ & $\begin{array}{r}1 \\
20\end{array}$ & $\begin{array}{r}2 \\
40\end{array}$ & $\begin{array}{r}1 \\
20\end{array}$ & $\begin{array}{r}1 \\
20\end{array}$ & $\begin{array}{r}5 \\
100\end{array}$ \\
\hline $20.000-49.999$ & $\begin{array}{lllll}\ldots & \ldots & \ldots & \ldots & \ldots\end{array}$ & $\%$ & $\begin{array}{r}2 \\
20\end{array}$ & $\begin{array}{r}4 \\
40\end{array}$ & & $\begin{array}{r}4 \\
40\end{array}$ & $\begin{array}{r}10 \\
100\end{array}$ \\
\hline $10.000-19.999$ & $\begin{array}{lllll}\ldots & \ldots & \ldots & \ldots & \ldots\end{array}$ & $\stackrel{n}{n}$ & $\begin{array}{r}1 \\
10\end{array}$ & $\begin{array}{r}4 \\
40\end{array}$ & $\begin{array}{r}3 \\
30\end{array}$ & 20 & $\begin{array}{r}10 \\
100\end{array}$ \\
\hline$<10.000(b)$ & $\begin{array}{lllll}\ldots & \ldots & \ldots & \ldots & \ldots\end{array}$ & $\stackrel{n}{n}$ & $\begin{array}{l}1 \\
6\end{array}$ & $\begin{array}{r}4 \\
24\end{array}$ & $\begin{array}{l}10 \\
59\end{array}$ & $\begin{array}{r}2 \\
12\end{array}$ & $\begin{array}{r}17 \\
101\end{array}$ \\
\hline TOTAL & $\begin{array}{llllll} & \ldots & \ldots & \ldots & \ldots & \ldots\end{array}$ & $\mathrm{n}$ & $\begin{array}{r}5 \\
12\end{array}$ & $\begin{array}{l}14 \\
33\end{array}$ & $\begin{array}{l}14 \\
33\end{array}$ & $\begin{array}{l}10 \\
23\end{array}$ & $\begin{array}{r}43 \\
101\end{array}$ \\
\hline
\end{tabular}

(a) El sector servicios incluye todas las actividades no relacionadas ni con la agricultura, ni con la industria, ni con el comercio.

(b) No incluye municipios con menos de 6.000 habitantes.

Fuente: Censo de Floridablanca.

\section{La nupcialidad en la España rural y urbana}

La nupcialidad es una variable demográfica de la mayor importancia, que demasiado a menudo se ha descuidado en favor del estudio de la mortalidad o la fecundidad (Wrigley, 1985). Su significado como institución reproductora de la sociedad cobra mayor relevancia allí donde el control de la fecundidad dentro del matrimonio es nulo o, a lo sumo, moderado. Este es, con certeza, 
el caso de España durante la mayor parte del período estudiado. Además, el matrimonio es no sólo el más consciente de los actos vitales, sino también el más determinado socialmente. Siendo esto asi, debería ser muy sensible a los cambios sociales impuestos por la vida urbana. En las sociedades tradicionales, las prácticas nupciales solían estar mediatizadas por el acceso a la tierra, la herencia $y / 0$ alguna otra forma significativa de sustento; $o_{2}$ como ha dicho un historiador, el matrimonio se pospondría hasta alcanzar un "nivel de vida minimamente adecuado» (Smith, 1981: 618). Una perspectiva tradicional consideraria, entonces, que donde la propiedad o la herencia se eliminaban como requisito para el matrimonio y la formación del hogar, como es el caso en un medio urbano, la nupcialidad se vería entonces liberada y se produciría a una edad más temprana y de forma más universal.

Una mirada atenta a las diferencias entre las prácticas nupciales del campo y la ciudad españoles mostrará en qué medida esta suposición carece de base histórica. La tabla 3 contiene información sobre $I m$ y la soltería permanente entre 1787 y 1930. La conclusión más inmediata que de ésta se obtiene es que la nupcialidad en las áreas urbanas es siempre inferior a la del campo. Durante casi un siglo y medio, la $I m$ urbana está en torno al 80 por 100 de la $I m$ rural. Sólo en 1920 y 1930 parecen acercarse las dos medidas, aunque la nupcialidad urbana es siempre, al menos, un 10 por 100 inferior. Es importante hacer notar que esta diferencia se debe más a los niveles prevalecientes de soltería que a la edad al matrimonio. Esto es evidente si examinamos los datos sobre soltería permanente, que en las ciudades oscila entre el 155 y el 240 por 100 de su equivalente rural. En otras palabras, las diferencias son considerablemente mayores que con $I m$. Más aún, la edad media al matrimonio (SMAM) en 1787 es sustancialmente la misma en ambas zonas, levemente mayor para los varones urbanos $(25,6$ vs. 25,1$)$ y levemente inferior para las mujeres de la ciudad $(23,2$ vs. 23,8).

En años sucesivos persisten estos resultados. En 1900, la SMAM para las mujeres urbanas es 26,0 , mientras que en las del campo es 24,5 ; en 1920 , las edades son, respectivamente, 26,7 y 25,5. Los gráficos 1, 2 y 3 ayudarán a ilustrar este punto. Observando las líneas de los porcentajes de mujeres solteras para tres años $(1787,1900$ y 1920), aparece nítidamente que el comportamiento es similar entre el campo y la ciudad durante las edades más tempranas. Para edades más elevadas, la ciudad muestra pronto importantes diferencias en la proporción de solteras, bastante superior en todos los grupos. Aquellas mujeres que se casan lo hacen aproximadamente a la misma edad, y las diferencias en $I m$ se deben a las mujeres que permanecen solteras, una tendencia que ya es evidente en el grupo de 20-24 años y que persiste durante todo el período fértil de las mujeres. 


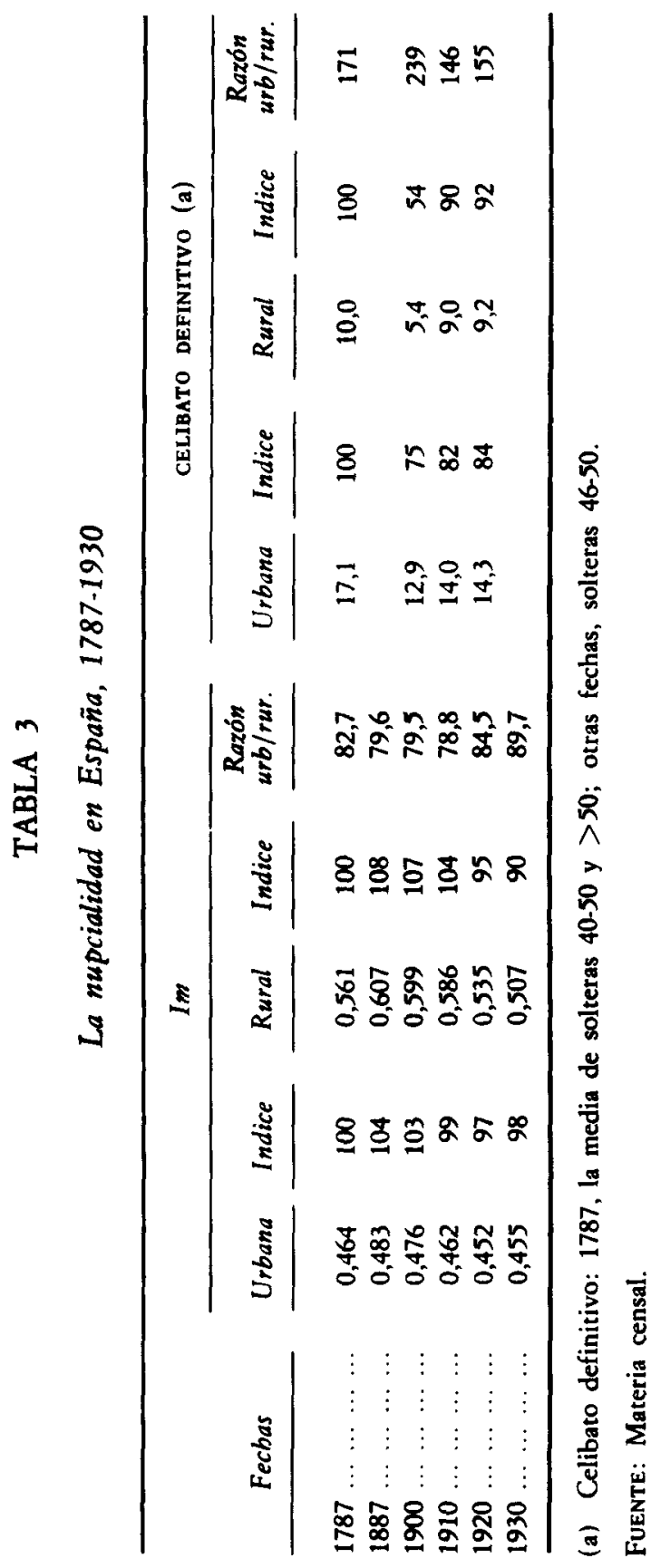







Podemos obtener información adicional sobre las prácticas matrimoniales en ambas zonas a través del examen de sus distintas proporciones de solteras y casadas. En la tabla 4 se aprecia que la diferencia entre las casadas de la ciudad y las del campo es bastante mayor que la diferencia entre las solteras de la ciudad y del campo, un fenómeno que crece con la edad y por el que sabemos que era mucho más fácil contraer segundas (y sucesivas) nupcias en el medio rural de lo que lo era en el medio urbano. De esta manera, en la ciudad no sólo se casan menos mujeres, sino que, además, un número menor de las que enviudan tienen la oportunidad de casarse de nuevo. Así queda severamente disminuida la capacidad reproductiva de las poblaciones urbanas, tanto por niveles más altos de soltería en todas las edades como por la menor incidencia de las segundas nupcias, el modo tradicional de mitigar los efectos negativos de la mortalidad adulta en la fecundidad femenina.

¿Cómo se explica esta nupcialidad tan restringida en las ciudades, donde no existen las limitaciones que impone el acceso a la tierra? Por desgracia carecemos todavía de estudios microdemográficos sobre áreas urbanas, y es difícil entonces contestar a esta pregunta con certeza. Pero ello no nos impide proponer algunas hipótesis bien fundadas. En primer lugar, es importante distinguir dos tipos de población urbana: una, originaria de la ciudad, y otra, compuesta por quienes han llegado a ella, en general con una edad entre los 15 y $\operatorname{los} 25$ años. Si de la primera es razonable suponer que goza de una situación social más o menos establecida, la segunda es, por definición, una población desarraigada. Estudiando el caso de Cuenca durante el siglo xix, hemos llegado a la conclusión de que la edad al matrimonio era un año y

\section{TABLA 4}

Proporciones solteras, proporciones casadas, rural y urbana, en 1900

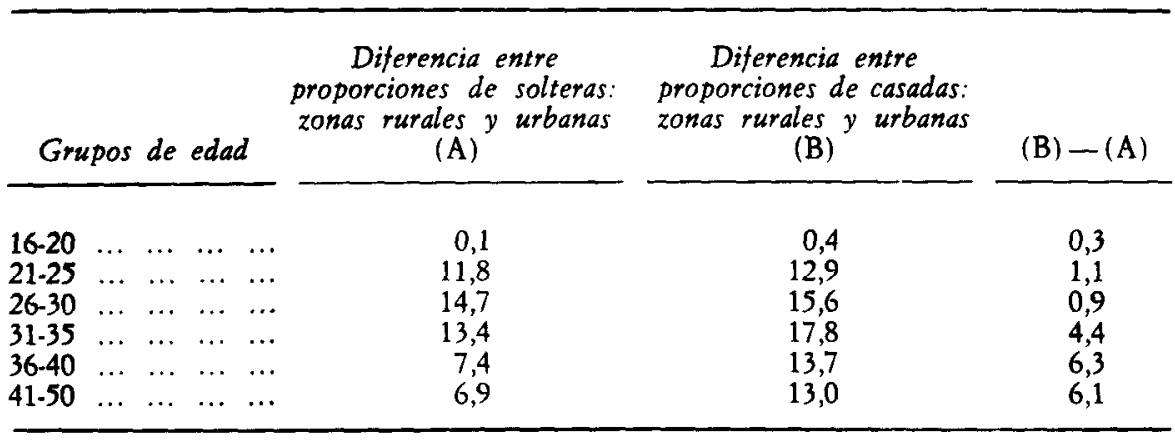

Fuente: Censo de 1900. 
medio más elevada entre los inmigrantes que entre los nacidos allí. La clase de empleo que buscaban los inmigrantes era completamente diferente al que tenía la población local. El servicio doméstico estaba al alcance de la mano de los llegados de fuera, y sus efectos eran un retraso del matrimonio e incluso, para el $10-15$ por 100 que lo desempeñaba durante toda su vida, una condena a la soltería. Quizá debamos recordar que este tipo de servicio doméstico apenas existía en el campo, mientras que en las ciudades podía suponer más del 10 por 100 de la población activa total.

Otros inmigrantes, como los trabajadores industriales (una minoría, con toda seguridad), podían ejercer profesiones que también dificultasen el matrimonio, sobre todo por lo difícil que resultaba reunir dinero suficiente para establecer un hogar. Asimismo debemos recordar una circunstancia habitual en zonas urbanas, en especial cuando incluían núcleos gubernamentales o militares de importancia (caso de ciudades como Palma de Mallorca, La Coruña, Cartagena, Cádiz, etc.): la razón de masculinidad, sobre todo para edades en torno a la de matrimonio, podia estar desajustada severamente. Otro hecho que hay que tener presente cuando se analizan las diferentes prácticas nupciales es que, si la emigración rural afectaba casi por igual a hombres y a mujeres (como parecen indicar los datos censales), el acceso al mercado matrimonial se vería facilitado a quienes no emigrasen por la mejora relativa de sus condiciones económicas. Aquellos destinados a ser protagonistas de la reproducción social en las zonas rurales permanecerían en el lugar o se desplazarían poco y cerca, por lo general; mientras que era probable que aquellos cuya reproducción no era necesaria y que se veían expulsados a la ciudad no llegasen nunca a casarse.

Por último, hay un aspecto de la cultura urbana que podría contribuir a explicar estas diferencias. En un área urbana, la presión social para contraer matrimonio era muy inferior a la que habría en un pueblo pequeño. La facilidad con que las mujeres encontraban trabajo en la ciudad, independientemente de su estado civil, y la mayor heterogeneidad de los núcleos urbanos reducirían el estigma social que acompañaba a los solteros en muchas regiones españolas. El mismo razonamiento puede aplicarse a las viudas urbanas, que no sentirían tanta presión económica y social para encontrar un nuevo marido lo antes posible. Las ciudades abundaban en viudas y viudos solitarios.

Las ciudades nunca se cerraban a su entorno rural, y los flujos migratorios que traían y sacaban a gente de ellas eran los canales en los que se manifiesta esta influencia mutua. Es más, como hemos mencionado más arriba, no era extraño que hubiese importantes poblaciones campesinas viviendo dentro de la ciudad, y ellas serían las más influidas por el núcleo urbano, como bien puede imaginarse; su comportamiento no sería del todo «urbano», pero tampoco debía ser completamente «rural». El censo de Floridablanca nos ofrece la oportunidad de averiguar en qué medida se distinguían estos dos tipos de 
población. Si tomamos los casos de Valencia, la segunda ciudad del país a finales del siglo xvin, y de Murcia, y seguimos la división que se hace entre «intramuros» y «extramuros», para Valencia, y «ciudad», «huerta» y «campo», para Murcia, nos queda una tabla como la 5.

TABLA 5

Im en Valencia y Murcia en 1787

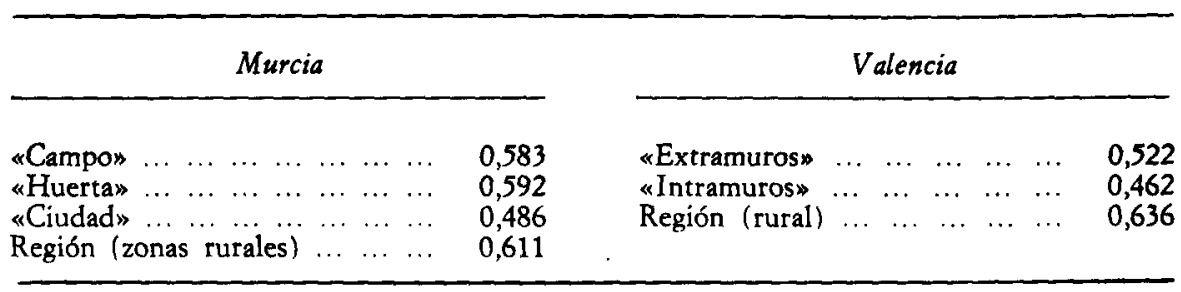

Fuente: Censo de Floridablanca.

En ella se dan las Im correspondientes, y se comprueba que estas poblaciones en torno a la ciudad no eran ni «rurales» ni «urbanas» en su comportamiento. Tanto en Valencia como en Murcia, la nupcialidad más baja se encuentra en la ciudad, mientras las cifras en su binterland quedan por debajo de las regionales. Aunque resulta extremadamente difícil dar una explicación clara para este fenómeno, podría muy posiblemente tener que ver con la realidad económica y cultural mixta de estas áreas: mientras el acceso a la propiedad determinaba todavía la entrada en el mercado matrimonial, en lo económico estaban prácticamente integradas en la ciudad. Allí irían a servir y trabajar los jóvenes, y a vender sus productos los campesinos y hortelanos, al igual que irían en caso de una crisis grave de subsistencia. Económica y culturalmente eran un híbrido, y así se manifiesta en sus pautas matrimoniales.

$\mathrm{La}$ evolución del matrimonio es también visible en la tabla 3 . El ascenso de la nupcialidad es innegable (aunque modesto) entre 1787 y 1887, tanto para el campa como para la ciudad. Este ascenso se debe a la caída de casi un 50 por 100 de la soltería permanente, que contrarresta el alza continua en la edad al matrimonio (hombres: 24,5 en 1787 y 25,0 en 1887; mujeres: 23,2 y 24,2, respectivamente), un alza que no se rompe hasta 1950 (Cachinero, 1982: 81-99). El nivel máximo de Im se alcanza entre 1887 y 1900 , desde donde comienza un ligero descenso, más evidente en la España rural. Como ocurriese antes, la fuerza oculta tras estas oscilaciones de $I m$ es el nivel de soltería, que en el siglo $\mathrm{xx}$ se combina con aumentos en la edad al matrimonio 
para reducir sensiblemente la nupcialidad. Las tendencias son las mismas en las áreas rurales y urbanas, aunque siempre más marcadas en el campo. En este punto son muy elocuentes los datos de soltería, donde las ratios urbano/ rural sufren oscilaciones fuertes. Los datos de esta clase sobre la nupcialidad podrían obligar, a quien se dedique a la historia de España, a reformular dos hipótesis tradicionales. En primer lugar, la prevalencia de la soltería sobre la edad al matrimonio en la explicación de los niveles de nupcialidad no es una hipótesis nueva, pero tampoco habitual en la historia de la población española (Wrigley y Schofield, 1981: 257-269). En segundo lugar, el pico en la curva de nupcialidad al final del siglo xix, junto con niveles especialmente altos de fecundidad, contribuyeron decisivamente a mantener el crecimiento de la población española durante este período.

¿Hasta qué punto afectaron a la población rural de una provincia sus concentraciones urbanas? Se ha repetido que eran numerosos los lazos entre la ciudad y el área rural circundante. La relación entre ambos mundos era tal que considerarlos por separado parecería una grave simplificación. El lazo más importante era, sin duda, el trasiego de personas. Aquí hemos hecho mención ya de la atracción que ejercía la ciudad hacia los emigrantes rurales. Este movimiento, sin embargo, no tiene siempre la ciudad por destino, sino que más bien es multidireccional. El mejor ejemplo es el caso del servicio doméstico que abunda en las ciudades. Este servicio provenia, sobre todo, de zonas rurales cercanas a la ciudad, y su estancia era temporal en la mayoría de los casos: justo lo suficiente como para conseguir el dinero para la dote o para ayudar a la economía familiar y volver a su pueblo de origen. Mientras el porcentaje de retorno tiende a variar según la ciudad, podemos asegurar que el desplazamiento al centro urbano no era normalmente definitivo. Para el caso de Cuenca, esta forma de flujo migratorio se ha calculado en torno al 10 por 100 anual, y afecta a todos los grupos de edad (Reher, 1986). Estos individuos son vehículo de comunicación económica y cultural entre la ciudad y el campo, y podrían ser los canales mediante los cuales la ciudad influía sobre el campo en aquellas provincias fuertemente urbanizadas.

La tabla 6 intenta determinar el grado de influencia de estas áreas fuertemente urbanizadas en su entorno. En él se han dividido las provincias españolas en cinco grupos diferentes, de acuerdo con su grado de urbanización. El grupo I corresponde a las dos provincias urbanas por excelencia, Madrid y Barcelona. El grupo II contiene las provincias con más de un 40 por 100 de su población residente en ciudades; este grupo está distorsionado por la presencia de Asturias y, en menor medida, por Cádiz y Murcia, ambas con más de una agrociudad importante. El grupo III incluye las provincias cuya población urbana oscila entre el 20 y el 30 por 100. En el grupo IV están aquellas fundamentalmente rurales, con una población urbana entre el 10 y el 19 


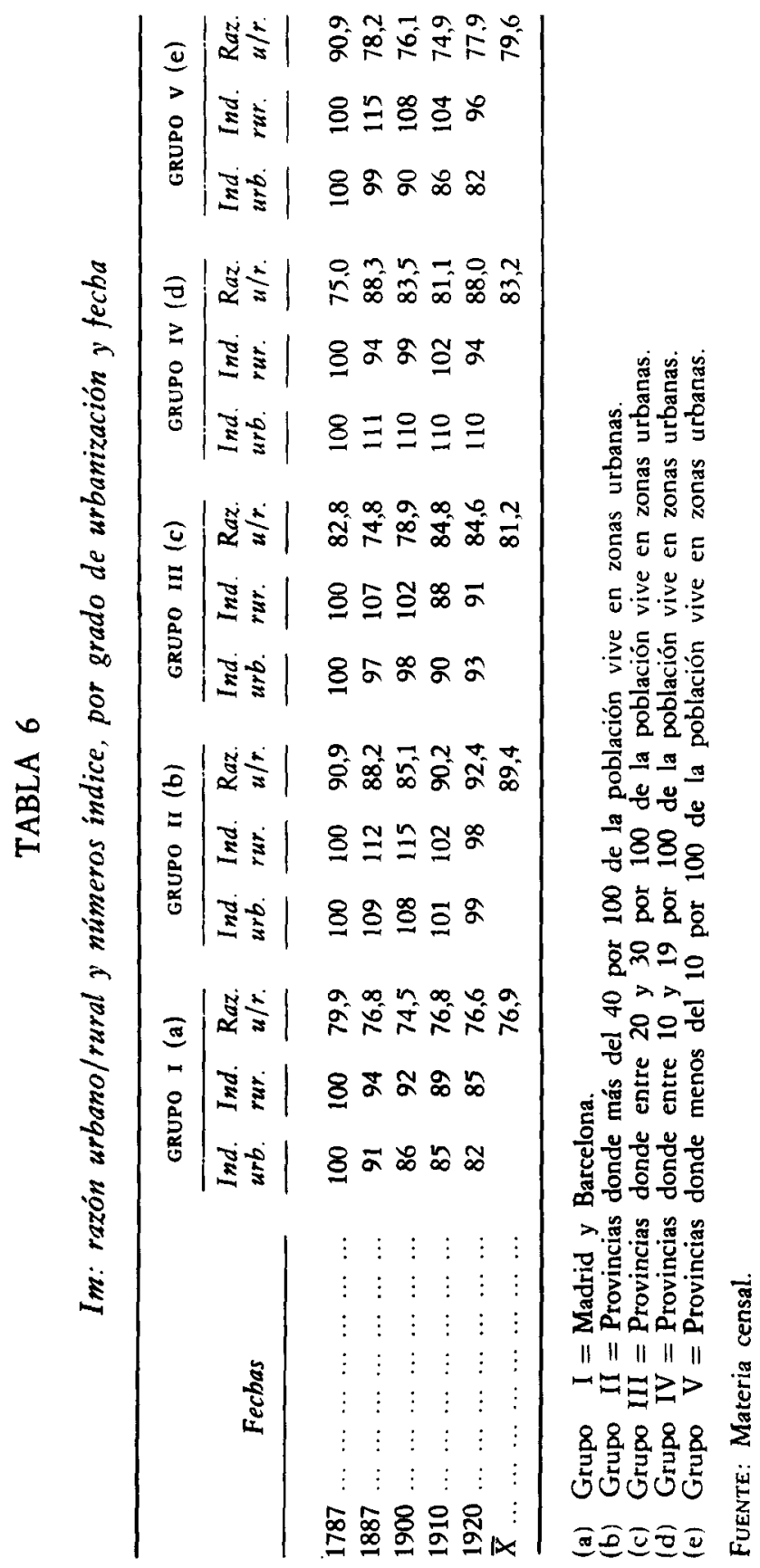


por 100 del total. El grupo $\mathrm{V}$ se compone casi por completo de las pequeñas capitales de provincia, calificadas como ciudad por su papel administrativo más que por su tamaño. Esta tabla 6 no incluye las respectivas $I m$ para cada uno de estos grupos, pues los modelos nupciales no sólo se deben a la concentración urbana, sino también a factores culturales que varían de provincia a provincia y que afectan a los índices tanto de la ciudad como del campo. Por esta razón sólo hemos utilizado los números índice, con la ventaja de medir así el cambio relativo de forma comparable.

Además, la tabla presenta los cocientes entre ciudad y campo para apreciar con claridad la diferencia entre ambas zonas. Aunque los resultados de la tabla no se interpretan con facilidad, parecen corroborar parcialmente las hipótesis anteriores. La razón de $I m$ ciudad/campo en el grupo I es casi siempre la más baja y la de menores oscilaciones. Por el contrario, es el grupo II, con todas las agrociudades, el que muestra las menores diferencias entre sus poblaciones urbana y rural. Ambas relaciones se explican por la población activa de sus ciudades. Ya entonces, Madrid y Barcelona eran ciudades sin apenas actividad agrícola, justamente al contrario que en los núcleos del grupo II. Las razones del grupo $\mathrm{V}$, muy bajas, se deben también a la población activa en sus centros, concentrada sobre todo en el sector terciario. Por las mismas circunstancias, en los grupos I y V, donde las poblaciones urbanas son menos agrícolas, su comportamiento matrimonial es el que más difiere entre la ciudad y el campo.

Si consideramos los cambios en su dimensión temporal, vuelven a sobresalir los resultados de Madrid y Barcelona. Sus poblaciones rural y urbana muestran un descenso pronunciado en su nupcialidad incluso en 1887 , período en el que la nupcialidad urbana crece ligeramente. Más importante es quizá la considerable similitud en la evolución de los índices del campo y la ciudad. Este descenso paralelo entre 1787 y 1920 parece sugerir que las ciudades ejercían una atracción importante sobre el campo, como muy bien se ve en el nivel ligeramente inferior del índice urbano; por tanto, un poco por delante del rural en su descenso común, separados de los índices del resto del país. El comportamiento de las otras categorías no es tan claro. Mientras en el grupo II los índices también se desplazan juntos, no muestran dirección alguna y, por tanto, no queda claro si se produce o no tal atracción. En el grupo III sí existe la tendencia, pero ambas curvas son muy dispares, sobre todo en 1787 y 1887 . Los grupos IV y V no muestran ninguna similitud, como podría esperarse de la parte menos urbanizada del país. Debe apreciarse, no obstante, que la parte urbana del grupo $\mathrm{V}$ sigue una trayectoria similar a la del grupo I, indicando de nuevo la importancia de la actividad de la población en su comportamiento demográfico. 
La fecundidad en la España rural y urbana

La nupcialidad es una institución social única en sus rasgos y en ella se unen la decisión consciente, la situación económica y familiar y las limitaciones sociales, y todos estos factores pueden ser muy diferentes en el campo y en la ciudad. ¿Tiene la fecundidad de una mujer las mismas características? Al contestar parece conveniente centrarnos en la fecundidad legítima, ya que la ilegitimidad raramente llegaba en el campo al 5 por 100 del total de nacidos y en la ciudad no solia pasar de un 12.13 por 100 . En otras palabras, cerca del 90 por 100 de la reproducción, incluso en las ciudades, tenía lugar dentro de la institución del matrimonio, y es aquí donde la capacidad reproductiva de una mujer mejor puede medirse. ¿Cómo es la fecundidad dentro del matrimonio, independientemente de la edad en que se casa una mujer, y cómo se diferencian los comportamientos en el campo y en la ciudad? Mientras la reproducción también es social en su naturaleza, en ausencia de un control generalizado de la fecundidad, no lo es tanto ni es tan consciente como lo es el matrimonio. ¿Cómo es la fecundidad allí donde la familia no depende de ingresos relativamente fijos y un niño puede suponer una ayuda para la economía familiar a partir de una edad relativamente joven? Una perspectiva materialista de la reproducción sugeriría que la fecundidad iría en incremento mientras la familia necesitase ingresos adicionales para contrarrestar la inestabilidad natural del mercado de trabajo capitalista (Smith, 1981: 613; Mendels, 1972; Medick, 1976). La evidencia histórica en el caso europeo muestra un saldo contrario: en las ciudades la fecundidad es no sólo inferior a la rural, sino que incluso comienza antes su descenso (Bardet, 1983; Perrenoud, 1979; Livi Bacci, 1983). ¿Qué conclusiones pueden derivarse de los datos españoles?

La tabla 7 contiene resultados de dos medias complementarias de fecundidad legítima: Ig y TFM. En ambos casos muestran una fecundidad significativamente inferior en las áreas urbanas. Con la excepción de 1930, en todas las fechas la fecundidad urbana es, al menos, un 15 por 100 menor a la rural, y el cambio en la ratio de 1930 sugiere que se estaban produciendo cambios importantes en la demografía de las ciudades, pero no en la del campo (Leasure, 1963: 274; Livi Bacci, 1968: 100). Estas diferencias en la fecundidad no son una consecuencia de una nupcialidad urbana menor, pues el denominador de los indicadores es siempre el total de mujeres casadas y no el total de mujeres. En otras palabras, la capacidad reproductiva de la ciudad acaba siendo sustancialmente menor a la del campo, por dos razones. Primera, son menos las mujeres que se casan en la ciudad y, por tanto, menos las susceptibles de tener hijos; y, segunda, cuando se casan su fecundidad global es un 15 por 100 menor que la de las mujeres del campo. La fecundidad ilegítima de la ciudad 


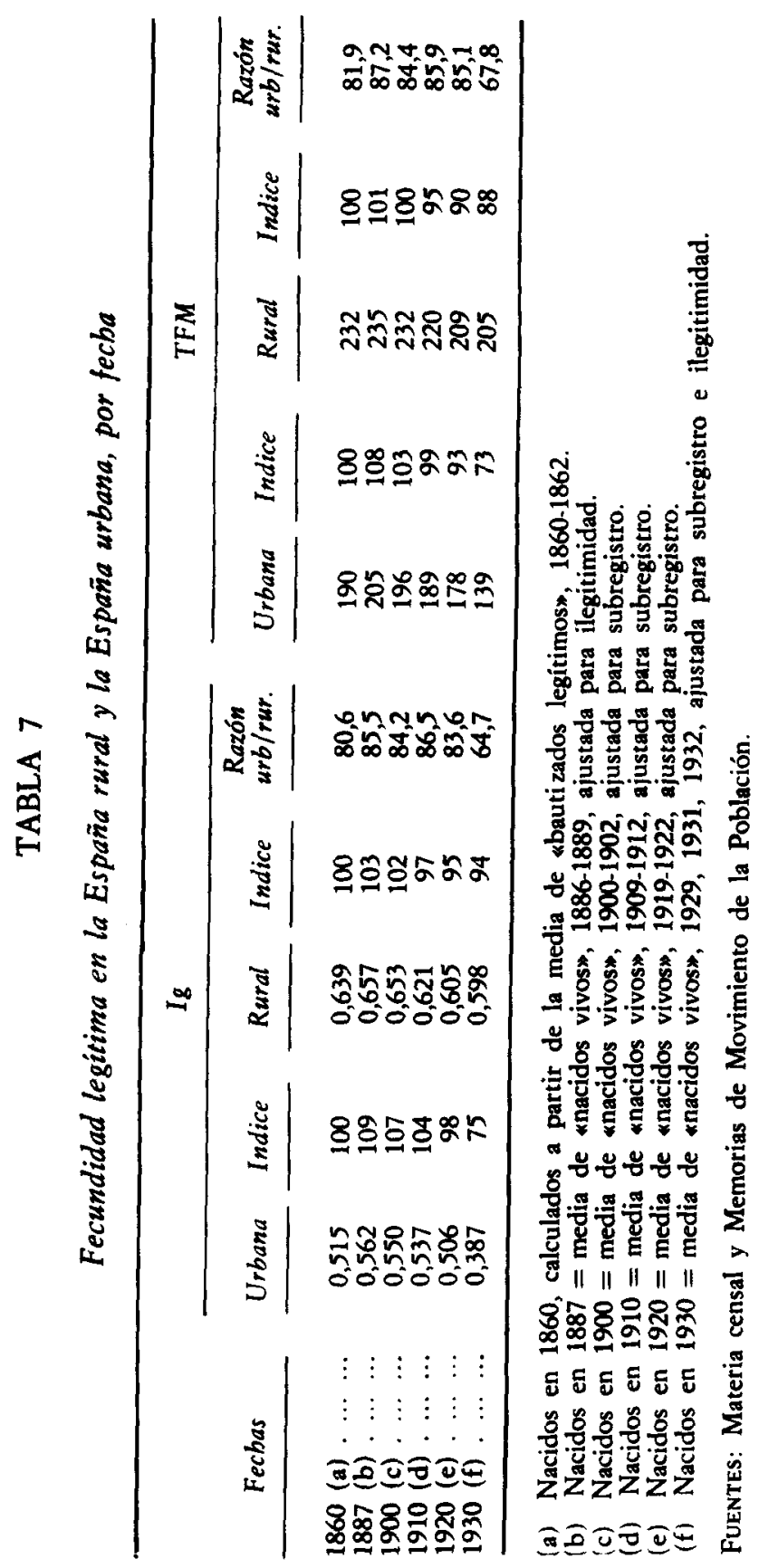


sólo neutraliza parcialmente esta diferencia, y en ningún caso compensa una nupcialidad entre $15-18$ por 100 inferior y una fecundidad marital que muestra diferencias similares.

Este comportamiento trae a colación dos interrogantes cuya contestación no es posible con los datos de que disponemos: ¿es común a todos los grupos de la ciudad esta fecundidad inferior?; ¿es fruto de condiciones sociales o biológicas, o se debe a un control consciente de la fecundidad? Con respecto al primer punto, la agregación de datos no permite una respuesta exacta, pero en la medida en que las diferencias persisten, y de forma tan pronunciada como se verá más adelante, en todo tipo de núcleo urbano, es improbable que algún grupo urbano no participase en mayor o menor medida en esa fecundidad inferior. Algunos estudios históricos han demostrado cómo los grupos privilegiados de sociedades urbanas fueron los primeros en disminuir su fecundidad, seguidos por otros sectores urbanos, que hicieron lo mismo con cierto retraso, pero siempre antes que en el campo (Bardet, 1983: 263). ¿Control consciente o simplemente una fecundidad inferior? Hay, por desgracia, pocas posibilidades de medir la fecundabilidad de las mujeres urbanas con los datos disponibles en España; pero, al menos en las clases inferiores y entre los inmigrantes, la movilidad espacial, el trabajo intensivo para hombres y mujeres y los salarios de subsistencia pudieron haber influido negativamente en la capacidad reproductiva de las mujeres. Entre los grupos más privilegiados, éste no sería el caso y el control de la natalidad era más que posible, y probablemente ocurriese lo mismo, en menor medida, con las clases bajas. En todo caso, la respuesta es incierta y la historiografía española habrá de esperar a futuros estudios microdemográficos acerca de la fecundidad diferencial y las pautas de matrimonio para llegar al fondo de este asunto.

Una cosa es la fecundidad reducida, característica de las sociedades urbanas, que puede haber estado presente durante siglos, y otra, completamente diferente, es un descenso significativo de la fecundidad. Como puede verse en la tabla 7 , no sólo no aparece un descenso significativo de la fecundidad hasta la última parte del período que estudiamos, sino que incluso ésta crece entre 1860 y 1887 . Este ascenso es mayor en las áreas urbanas que en las rurales, aunque la caída siguiente, que se inicia en 1887 y 1900 , respectivamente, es también algo más pronunciada para las ciudades, y a partir de 1920 lo es de forma muy significativa. Mientras el aumento más pronunciado de la fecundidad en las zonas urbanas de 1887 es sorprendente, podría responder a una intensificación de la fecundidad como consecuencia de la proletarización progresiva de las clases populares (Birdsall, 1983); ambas tendencias muestran un considerable paralelismo hasta 1920, indicando así que, si bien algo mayor en las ciudades, ambas zonas participaban en una tendencia nacional levemente descendiente. 
La influencia de estas oscilaciones en la fecundidad en las tasas de crecimiento españolas está ahora más clara. La tasa de crecimiento fue del 0,43 por 100 anual entre 1860 y 1887 ; del 0,45 por 100 entre 1887 y 1900; subió al 0,70 por 100 en la década siguiente; bajando al 0,66 por 100 entre 1910 y 1920; para subir al 1,01 entre 1920 y 1930 . Durante la primera parte de este período, el papel de la fecundidad es importante para el mantenimiento de las tasas de crecimiento, pues la mortalidad apenas parece descender y, debido a las epidemias de cólera de los años ochenta, hasta llega a subir. Podemos atribuir el aumento súbito de las tasas de crecimiento entre 1900 y 1910 al efecto conjunto de una fecundidad que apenas desciende y a la caída de la mortalidad (la tasa bruta de mortalidad pasa de 30,7 a 25,0 ). El descenso de la fecundidad en 1920 es más importante que el de la década anterior, aunque también modesto, y la mortalidad moderó su caída debido a la epidemia de gripe de 1918. A pesar de todo ello, persiste el crecimiento acelerado. Sólo durante el decenio siguiente bajará la fecundidad con claridad, pero a estas alturas la mortalidad y su descenso parece arrogarse el papel determinante en matener unos ritmos de crecimiento en ascenso. Lo importante es, sin embargo, el papel decisivo que tiene el crecimiento o, cuando menos, la estabilidad de las pautas de fecundidad durante el período 1887-1920, interrumpiendo su caída secular iniciada en el siglo xvin para sostener el crecimiento de la población al principio y complementar a la caída de la mortalidad después ${ }^{3}$.

Por último, la caída de la fecundidad urbana desde 1930 indica que la transición demográfica había comenzado ya en las ciudades. El descenso es muy pronunciado, más de un 20 por 100 en una década, e indica la clara posibilidad de un empleo más o menos extendido de medidas de control de la natalidad. Por otra parte, las áreas rurales persisten en el lento descenso de la fecundidad en el que acompañaron a las ciudades durante más de un siglo y medio. Esta divergencia de los comportamientos rural y urbano podría indicar que cualquier hipotético control de la fecundidad sería un ajuste inducido culturalmente a las cambiantes condiciones demográficas y sociales $\mathrm{y}$, como tal, apareció primero en las ciudades y se extendió luego al campo. Los altos niveles de alfabetismo y educación tendrían bastante influencia en este punto. Posteriormente fueron canales de comunicación cultural, económica y humana los que llevarían esta tendencia a las zonas rurales, ayudados por ciertos lazos culturales y lingüísticos que explican la diferente difusión en distintas regiones (Arango, 1980: 190-192).

\footnotetext{
${ }^{5}$ Estas cifras de fecundidad son, por lo general, similares a las encontradas por Livi Bacci, con excepción de las correspondientes al período 1860-1887, en el que sus datos muestran un descenso ligero pero continuo, mientras en los nuestros aparece un ascenso también débil. Esta discrepancia se debe, posiblemente, a la necesidad de estimar las proporciones de casadas para el censo de 1860.
} 
Debemos preguntarnos, una vez más, si esta comunicación constante que unía a ambos mundos pudo ser el instrumento mediante el cual los cambios en la fecundidad se extendían de la ciudad al campo, sobre todo en las provincias más urbanizadas. Como ocurre con la nupcialidad, los datos correspondientes a la fecundidad se agrupan, según los niveles de urbanización de la provincia, en la tabla 8. Los resultados no son muy concluyentes. En los grupos I y III, que contienen los mayores centros urbanos, las fecundidades rural y urbana descienden de forma más firme y paralela que en cualquiera de los otros grupos. Sin embargo, la del campo desciende por delante de la urbana y surge la duda sobre cuál de las dos, si alguna, marcaba el camino. Probablemente, la realidad es que la fecundidad iba descendiendo más o menos al ritmo de las tasas nacionales y no existía posibilidad alguna de provocar un cambio en las áreas rurales hasta que sucediese un cambio de importancia en alguna de las dos zonas, como ocurrió en las ciudades en 1930. Sin embargo, el descenso similar en los índices señala con seguridad que las tendencias de la fecundidad rural y urbana están más relacionadas en los grupos I y III que en ninguno de los otros grupos, de menor urbanización.

Finalmente, otro factor que influye en los niveles de fecundidad es el tamaño del área urbana. Cuanto más grande sea ésta, menor es la fecundidad, como puede verse en la tabla 9 , donde los distintos $I g$ se presentan según el tamaño de la ciudad. A lo largo del período estudiado, la fecundidad de las ciudades con más de 100.000 habitantes es un 13 por 100 inferior al de las ciudades entre 50.000 y 99.999 habitantes, y un 16 por 100 inferior al de las ciudades desde 20.000 a 49.999 habitantes. Es importante esta relación negativa entre fecundidad y tamaño, pues parece indicar que la aglomeración humana es un factor decisivo en la fecundidad, con independencia de la composición de la población activa.

\section{Algunas conclusiones}

A fin de situar con precisión el papel desempeñado por las ciudades a la hora de condicionar tanto los niveles como los cambios en la fecundidad y la nupcialidad, es preciso primero calibrar la importancia del proceso de urbanización durante los siglos XIX y xx; proceso, por otra parte, común a todo el continente europeo. Mientras que en 1700 el peso de las poblaciones urbanas era muy pequeño, incluso en países tan urbanizados como Holanda e Inglaterra, para 1900 eran varias las naciones con una proporción importante de residentes en ciudades. En 1800, Europa podía jactarse de tener 23 ciudades mayores de 100.000 habitantes, con un promedio de 239.000 habitantes; para 1900 eran ya 135 las ciudades y 341.000 habitantes su media. Al principio, 


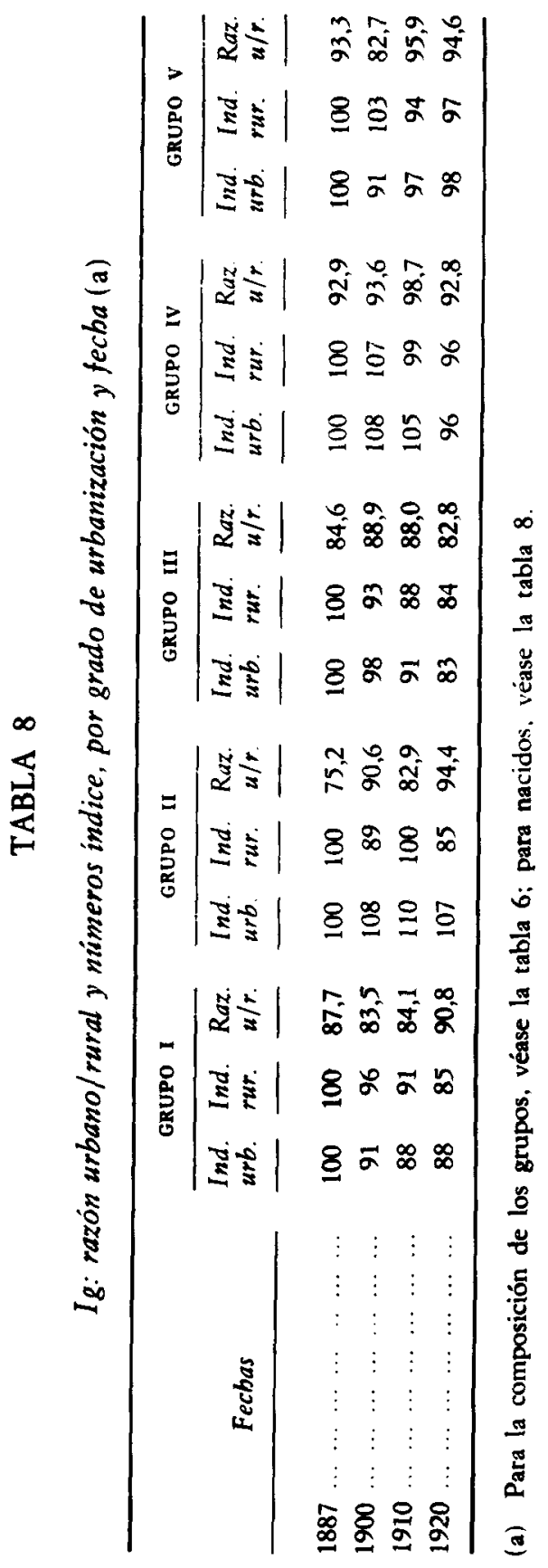




\section{TABLA 9}

Ig por tamaño de la ciudad y fecha

\begin{tabular}{|c|c|c|c|c|c|c|}
\hline \multirow[b]{3}{*}{ Fechas } & \multicolumn{6}{|c|}{ POBLACION } \\
\hline & \multicolumn{2}{|c|}{$>100.000$} & \multicolumn{2}{|c|}{$50.000-99.999$} & \multicolumn{2}{|c|}{$20.000-49.999$} \\
\hline & $\lg$ & Indice & Ig & Indice & Ig & Indice \\
\hline $\begin{array}{llllllllll}1860 & \ldots & \ldots & \ldots & \ldots & \ldots & \ldots & \ldots\end{array}$ & 0,484 & 100 & 0,566 & 100 & 0,585 & 100 \\
\hline $\begin{array}{lllllllll}1887 & \ldots & \ldots & \ldots & \ldots & \ldots & \ldots & \ldots\end{array}$ & 0,519 & 107 & 0,540 & 95 & 0,563 & 96 \\
\hline $1900 \ldots \ldots \ldots \ldots$ & 0,482 & 100 & 0,573 & 101 & 0,590 & 101 \\
\hline $1910 \ldots \ldots \ldots \ldots$ & 0,459 & 95 & 0,489 & 86 & 0,578 & 99 \\
\hline $1930 \ldots \ldots \ldots$ & 0,334 & 69 & 0,444 & 78 & 0,406 & 69 \\
\hline
\end{tabular}

Fuentes: Materia censal y Memorias de Movimiento de la Población.

este crecimiento urbano era compatible con el aumento de la población rural, hecho que se debió a la pujanza demográfica en zonas rurales de toda Europa durante la mayor parte del siglo xIx. A finales de siglo, sin embargo, eran varias las áreas en las que la población rural no sólo crecía menos que la media nacional, sino que incluso disminuía en cifras absolutas. En este sentido, Inglaterra y Francia fueron los pioneros en el siglo xix de una tendencia que se haría casi universal en el siglo xx (Armengaud, 1981). Este crecimiento de las ciudades se apoyaba en oportunidades económicas urbanas (servicio doméstico, comercio industrial, burocracia oficial y otros puestos en el sector de servicios) y, quizá en menor grado, crecientes dificultades en el mundo rural, donde, a pesar de importantes medidas que liberalizaban la tenencia de propiedad, la disponibilidad de tierra no podía de ninguna manera compensar el aumento de la población. En otras palabras, confluyeron a la vez causas de expulsión y atracción de la población, pusb y pull.

Como ya se ha dicho, España también participó en el gran proceso de urbanización europea, si bien su intensidad fue menor aquí que en otros muchos países más industrializados. Entre 1787 y 1930, el ritmo global de crecimiento urbano fue un robusto 1,14 por 100 al año, casi el triple del crecimiento rural. Además, abundan los ejemplos de crecimiento espectacular. La población de Bilbao pasa de 17.969 en 1860 a 161.987 en 1930. La población de Cartagena se multiplicaba por 5 entre 1787 y 1930; la de Gijón, por 7, y la de Barcelona, por 10. Sin embargo, este ritmo queda rezagado con respecto a otros países. Sólo una ciudad española pasa del millón de habitantes, y eso en 
1930. En 1850, Gran Bretaña tenía 28 ciudades con más de 50.000 habitantes, que sumaban 5,7 millones de personas y casi una quinta parte de la población. En España, en 1887, había 16, que representaban el 11,5 por 100 de la población total. En 1911, Francia tenía 16 ciudades con más de 100.000 habitantes; España tenía 8 en la misma fecha. En 1900 había 73 ciudades alemanas con más de 50.000 habitantes, mientras que en España había 18. Es evidente que el proceso de urbanización en España no era comparable, y más bien tendría que compararse con el de otros países mediterráneos tales como Italia, que en 1910 tenía 13 ciudades con más de 100.000 habitantes, frente a las 8 españolas. Por lo tanto, debido a estos distintos ritmos de urbanización, su importancia demográfica a escala nacional sería menor en España que, digamos, en Alemania, Inglaterra, Francia o incluso Italia.

No obstante, tanto en España como en otros países, los datos que obran en nuestro poder revelan que las ciudades mismas, independientemente del peso global de la población urbana, tuvieron un papel decisivo en la determinación del comportamiento demográfico de sus ciudadanos. En zonas urbanas, tanto la fecundidad como la nupcialidad oscilaron, de una forma continuada, entre el 10 y el 20 por 100 por debajo de los niveles correspondientes en el campo. Aunque ambas variables permanecían bajas en las zonas urbanas, ello no era necesariamente por las mismas razones. Mientras factores tales como el tipo de trabajo en la ciudad, los desajustes de la ratio de sexos, la disponibilidad de vivienda, la movilidad inherente a todos los emigrantes y los cambios en la mentalidad tradicional causados por la vida urbana influían a las personas a la hora de decidir su matrimonio, las limitaciones urbanas a la fecundidad estarían más directamente relacionadas con la dieta, el estrés urbano, el trabajo intensivo y continuo para uno y otro y otros aspectos menos visibles de la vida urbana. Pautas similares se pueden vislumbrar en Bélgica, Alemania, Italia, Portugal e Inglaterra, donde la fecundidad legítima y también la intensidad de la nupcialidad tendían a ser inferiores en las ciudades, a menudo en proporciones similares a las que se hallan en España (Livi Bacci, 1971: 105-111, y 1977: 110-134; Knodel, 1974: 88-110; Lesthaeghe, 1977: 114-119). Unicamente Francia y, acaso, partes de Suiza parecen dar la nota discordante. Alli, debido posiblemente a la costumbre de enviar a los recién nacidos fuera de la ciudad con amas de cría, con el consiguiente acortamiento del período de lactancia de la madre, la fecundidad urbana resulta superior a la de las zonas rurales, si bien los indicios de control de la natalidad parecen imponerse primero en las ciudades (Bardet, 1983; Perrenoud, 1979).

A este respecto, y a modo de hipótesis, parece posible que la decisión consciente desempeñe un papel complementario y vital en la determinación de estas prácticas urbanas, aunque la importancia de las restricciones auto- 
impuestas variaría con el grupo social a que se pertenecía. A pesar de la falta de estudios microdemográficos sobre áreas urbanas, es plausible considerar a la ciudad como compuesta por diferentes grupos sociales, cada uno de ellos basando su comportamiento en la conjunción de sus propias expectativas económicas y sociales. Con alguna simplificación, podemos considerar a la sociedad urbana como la suma de tres grupos básicos. En primer lugar, trabajadores, peones e inmigrantes ocupados como servicio doméstico en general sumaban la mayoría de la población de la ciudad. Este grupo era altamente móvil y regresaría a menudo a su lugar de origen tras una corta temporada en la ciudad, donde se sentirían tan desarraigados como acabarían sintiéndose en su pueblo. En segundo lugar, con un porcentaje inferior, estaban las clases trabajadoras afincadas en la ciudad, casi siempre descendientes en segunda o tercera generación de inmigrantes que se establecieron ahí de forma permanente. Por último, encontramos lo que podemos llamar élites, compuestas de miembros de profesiones liberales, empleados de la administración pública, burgueses, nobles y rentistas del campo o de la propia ciudad. El comportamiento de estos tres grupos respondía a factores muy diferentes y no sería en absoluto idéntico, por más que estuviese aún más alejado del comportamiento de la sociedad rural. Para los inmigrantes serían condicionamientos externos, sociales y económicos los que determinasen su actuación; para ellos habría fuertes restricciones al matrimonio y la fecundidad se debería más al nivel de vida que a decisiones conscientes, al no suponer los niños una desventaja económica. Las clases obreras urbanas, con estabilidad más que riqueza, tendrían los niveles más altos tanto de nupcialidad como de fecundidad, a pesar de ciertas similitudes con los inmigrantes. Y el comportamiento demográfico de los sectores privilegiados sería siempre más restringido y controlado que en los demás grupos. En el caso de Cuenca en el siglo xix, su edad al matrimonio y sus niveles de soltería permanente son superiores a los de cualquier otro sector social, y no hay razones para pensar que no es también así en el resto de las sociedades urbanas. El matrimonio tardío se debía, normalmente, a la prolongación de los estudios o la consecución del prestigio social necesario para «hacer una buena boda». Estos mismos factores podían ser la causa de niveles más altos de soltería definitiva; como podía serlo también la antigua costumbre de enviar a los hijos menores a la Iglesia o al ejército; de esta forma se les dificultaba la posibilidad de procrear. Una menor mortalidad y la necesidad de asegurarse un nivel de vida aceptable para ellos y sus descendientes les llevarían a estas élites a ser los verdaderos pioneros en el control de la fecundidad. En otros países han aparecido ya pruebas convincentes a este respecto, y parece razonable suponer que en España la situación sería similar, aunque sigue siendo necesario esperar a estudios locales que corroboren o refuten estas hipótesis. 
El importante declive de la ya baja fecundidad que aparece en los datos de 1930 parece deberse a la generalización de las actitudes restrictivas a otros grupos urbanos y a un descenso en la natalidad de todos ellos. La educación no debe descartarse como uno de los factores más importantes, pero no debemos menospreciar la probabilidad de un proceso de ajuste como respuesta a la rápida disminución de la mortalidad infantil (Carlsson, 1967). El período que va desde 1900 a 1915 se caracteriza por un descenso modesto en la mortalidad de párvulos y recién nacidos, mayor en el campo que en las ciudades, que acaba con un alza transitoria al final de la década. A partir de 1920 el descenso será dramático, por encima del 15 por 100 entre 1920 y 1930 , y afecta menos al campo que a las ciudades. Sólo a partir de ese momento cae claramente la fecundidad en las áreas urbanas. El conocimiento de los medios de control de la fecundidad, que posiblemente ya existía en ellas, podía convertirse en un mecanismo de ajuste efectivo. Las áreas rurales, sin experiencia en este control, ajustaron su población enviando emigrantes a las ciudades durante toda la década, y fue mucho más tarde cuando la contracepción llegó a ellas.

Aparte del descenso de ambas variables en el conjunto nacional, estimulado por el peso numérico creciente de las poblaciones urbanas, ¿qué influencia tuvieron las ciudades en los niveles y tendencias del campo? Que la influencia existe parece claro, pero no lo son tanto ni sus características ni su direccionalidad. La cercanía de una gran ciudad o de una provincia muy urbanizada, un sumidero para la juventud rural en busca de empleo, podría provocar tanto el descenso como el ascenso de la nupcialidad. Lo primero ocurriría por el retraso que impone ir a la ciudad, ocuparse en una profesión que implica restricciones a la nupcialidad y volver más tarde al pueblo para casarse. También podría haber una asimilación de las pautas culturales urbanas, traídas por los que en ella habían trabajado. Pero también podemos pensar en el caso contrario: al haber ciudades cerca y emigrar a ellas quienes más difícilmente se hubieran casado, quedaban quienes mejor podían hacerlo, sobre todo en la nueva situación económica y social del pueblo. Desde esta perspectiva es posible entender los niveles más bajos de la nupcialidad urbana como consecuencia de la presión demográfica en las áreas rurales en torno a las ciudades. La baja fecundidad urbana y el crecimiento de las ciudades serían, por el contrario, un escape para las zonas rurales, que podrían enviar a los jóvenes a la ciudad y sentir menos la necesidad de compensar el descenso de la mortalidad (Knodel, 1974: 272). Por el contrario, las influencias culturales de las grandes ciudades en su binterland tenderían a producir un descenso en la fecundidad. Por desgracia, estas ideas han de quedar como meras hipótesis, ya que los datos de que disponemos hasta ahora no son suficientes, y más sólidas conclusiones tendrán que aguardar a nuevos trabajos en este campo. 


\section{BIBLIOGRAFIA}

Arango, J. (1980): "La teoría de la transición demográfica y la experiencia histórica», Revista Española de Investigaciones Sociológicas, 10 (abril-junio), pp. 169-198.

Armengaud, A. (1981): «La población en Europa, 1700-1914», en Cipolla, Carlo M. (ed.): Historia Económica de Europa, vol. III: «La Revolución Industrial», Barcelona.

BARDET, P. (1983): Rouen aux XVII' et XVIII' siècles. Les mutations d'un espace social, Parîs.

Birdsall, N. (1983): «Fertility and Economic Change in Eighteenth and Nineteenth Century Europe. A Comment», Population and Development Review, 9, 1, pp. 111-123.

CACH INERO, B. (1982): «La evolución de la nupcialidad en España (1887-1975)», Revista Española de Investigaciones Sociológicas, 20, pp. 81-99.

Carlsson, G. (1967): «The decline of fertility: innovation or adjustment process», Population Studies, 20 , pp. 149-174.

Conle, A. (1965): «Factors Associated with the Development of Low Fertility: An Historic Summary», en Naciones Unidas, World Population Conference, 2, pp. 195-209.

- (1969): "The Decline of Fertility in Europe from the French Revolution to World War II , en Behrman, S. J.; Corsa, L., y Freedman, R. (eds.) (1969): Fertility and Family Planning, Ann Arbor, pp. 3-24.

Df́zz Nicolás, J. (1972): Especialización funcional y dominación en la España urbana, Madrid.

Gómez Redondo, R. (1984): «Mortalidad infantil real frente a mortalidad infantil legal», Boletín de la Asociación de Demografía Histórica, 2, 1, pp. 6-19.

KNODEL, J. E. (1974): The Decline of Fertility in Germany, 1871-1939, Princeton.

LEASURE, W. (1963): «Factors Involved in the Decline of Fertility in Spain, 1900-1950», Population Studies, 16, 3, pp. 271-285.

LEST H AEG HE, R. J. (1977): The Decline of Belgian Fertility, 1800-1970, Princeton.

Lrvi Bacci, M. (1968): «Fertility and Nuptiality Changes in Spain from the Late 18th to the Early 20th Century», Population Studies, 22, 1, pp. 83-102, y 2, pp. 211-234.

- (1971): A Century of Portuguese Fertility, Princeton.

- (1983): «Ebrei, Aristocratici, Cittadini: Precursori del Declino della Fecondità», Quaderni Storici, 54, XVIII, 3, pp. 931-937.

- (1977): A History of Italian Fertility during the Last Two Centuries, Princeton.

Medick, H. (1976): «The Protoindustrial Family Economy: the Structural Function of Household and Family during the Transition from Peasant Society to Industrial Ca. pitalism», Social History, 3, pp. 291-315.

Mendels, F. (1972): «Protoindustrialization: the First Phase in the Process of Industrialization», Journal of Economic History, 32, pp. 241.261.

Pérez Moreda, V. (1985): "La población española en el siglo xix y el primer tercio del xx (Limitaciones y cronología de la modernización demográfica en España)», en SÁnC h EZ-Albornoz, N. (ed.): La modernización económica de España, 1830-1930.

Perrenoud, A. (1979): La population de Genève du seizième au début du dixneuvième siècle, Ginebra.

REHER, D. S. (1986): «Mobility and Migration in Pre-Industrial Urban Areas: The Case of Nineteenth Century Cuencam, ponencia presentada en el Seminario de la UIESP acerca de Urbanización y Dinámica de Población en la Historia.

Rodrfguez Osuna, J. (1983): «Proceso de urbanización y desarrollo económico en España», Ciudad y Territorio, $1 / 83$, núm. 55, pp. 25.54.

SMITH, R. M. (1981): «Fertility, Economy, and Household Formation in England over Three Centuries", Population and Development Review, 7, 4, p. 618.

WrIGLEY, E. A. (1985): «Las perspectivas de la Historia de la población en la década de los 80», Boletín de la Asociación de Demografía Histórica, III, 2, pp. 4-31; publicado originariamente en The Journal of Interdisciplinary History.

WRIGley, E. A., y SCH OfIEld, R. S. (1981): The Population History of England, 1541. 1871: A Reconstruction, Londres-Cambridge. 